\title{
EFEKTIVITAS METODE CERAMAH DAN DISKUSI KELOMPOK TERHADAP KEPATUHAN REMAJA MENGKONSUMSI TABLET TAMBAH DARAH
}

\author{
Linda Suryani \\ PSD III Kebidanan, STIKes Payung Negeri Pekanbaru \\ Jl. Tamtama No 6 Labuh Baru. Pekanbaru-Riau-Indonesia \\ Email: linda.suryani@payungnegeri.ac.id
}

\section{Kata Kunci :}

Metode Ceramah, Diskusi Kelompok, Remaja, Tablet Tambah Darah

Keywords:

Lecture Method, Group Discussion, Adolescent, added blood tablet

\section{Info Artikel}

Tanggal dikirim: 26-12-2020

Tanggal direvisi: $8-1-2020$

Tanggal diterima: 23-1-2020 DOI :

10.36341/jomis.v4i1.1110 Attribution-NonCommercial 4.0 International. Some rights reserved

\begin{abstract}
ABSTRAK :
Remaja putri salah satu kelompok yang rawan terhadap defisiensi zat besi karena dalam masa pertumbuhan puncak. Pemberian tablet tambah darah sebagai salah satu upaya pencegahan dan penanggulangan anemia. Data Riskesdas 2018, 76,2\% remaja putri telah mendapatkan tablet tambah darah di sekolah, dari 76,2\% yang mendapatkan tablet tambah darah hanya $80,9 \%$ yang mengkonsumsi tablet tambah darah. Tujuan penelitian ini adalah untuk mengetahui efektivitas metode ceramah dan diskusi kelompok terhadap kepatuhan remaja dalam mengkomsumsi tablet tambah darah. Jenis penelitian adalah kuantitatif, desain penelitian Quasi eksperimen menggunakan metode Non quivalent Control Group Design. Penelitian dilakukan di SMP Negeri 16 Pekanbaru pada bulan November 2019. Populasi dalam penelitian ini adalah seluruh remaja putri yang ada di SMP Negeri 16 Pekanbaru berjumlah 384 orang, sampel remaja puteri umur 15 tahun yang berjumlah 60 Orang. Pengambilan sampel dengan cara total sampling. Instrumen penelitian adalah kuesioner. Pengolahan data dengan editing, coding, Entry dan tabulating. Analisa yang digunakan adalah analisa univariat dan bivariate menggunakan uji T-test dependent/ t- paired test, Hasil uji statistic nilai $\mathrm{P}$ value $=0,000(0,000<0,05)$. Artinya ada perbedaan yang signifikan antara sebelum dan sesudah dilakukan metode ceramah dan diskusi kelompok. Dapat disimpulkan bahwa metode promosi kesehatan yang paling efektif dalam meningkatkan kepatuhan remaja putri dalam mengkonsumsi tablet tambah darah adalah metode diskusi kelompok. Diharapkan pihak SMP Negeri 16 Kota Pekanbaru bekerja sama dengan instansi kesehatan lainnya untuk dapat meningkatkan promosi kesehatan kepada remaja putri khususnya tentang tablet tambah darah dengan metode diskusi kelompok.
\end{abstract}

\section{ABSTRACT :}

Adolescent girls one of a group that is vulnerable to iron deficiency because their peak growth period. Giving blood added tablets as an effort to prevent and control anemia. Riskesdas 2018, 76.2\% adolescent girls have received blood-added tablets at school, of $76.2 \%$ who get blood-added tablets only $80.9 \%$ consume blood-added tablets.The purpose of this study was to determine the effectiveness lecture methods and Group Discussion on adolescent adherence of girls in consuming blood-added tablets. This type of research is quantitative, the quasi experimental research design uses the method of Non quivalent Control Group Design. The study was conducted in Junior High School 16 Pekanbaru in November 2019. The population in this study were all adolescent girls in Junior High School 16 Pekanbaru, amounting to 384 people, a sample of 15-year-old adolescent girls totaling 60 people. Sampling by total sampling. The research instrument was a questionnaire. Data processing by editing, coding, entry and tabulating. The analysis used is univariate and bivariate, analysis using the T-test dependent / $t$-paired test. The statistical test results obtained $P$ value $=0,000$ (0,000 <0.05). This means that there are significant differences between before and after using the lecture method and group discussion. Concluded a method of promoting the health of the most effective in improving compliance adolescent girls in consume tablet added blood is the group discussion method. It is expected that the Junior High School 16 Pekanbaru in collaboration with other health agencies can improve health promotion for adolescent girls, especially on blood-added tablets with the group discussion method. 


\section{PENDAHULUAN}

Remaja putri salah satu kelompok yang rawan terhadap defisiensi zat besi dikarenakan sedang dalam masa pertumbuhan puncak (peak growth). Hal ini mengakibatkan remaja putri lebih rawan terhadap anemia [1]

Pemberian tablet tambah darah sebagai salah satu upaya dalam pencegahan dan penanggulangan anemia. Di Indonesia, tablet tambah darah sudah lama diberikan secara rutin pada wanita usia subur khususnya ibu hamil di Puskesmas dan Posyandu, namun sejauh ini hasil yang dicapai belum menggembirakan, terbukti masih tingginya prevalensi anemia pada wanita usia subur dan Ibu hamil [2]

Data Riskesdas 2018, menyebutkan bahwa prevalensi Anemia pada ibu hamil 48,9\%. Hal tersebut merupakan dampak lanjut dari tingginya prevalensi anemia pada remaja puteri sekitar $25 \%$ dan pada wanita usia subur sekitar $17 \%$. Dari data Riskesdas 2018, menyebutkan 76,2\% remaja putri telah mendapatkan tablet tambah darah di sekolah, dari 76,2\% yang mendapatkan tablet tambah darah hanya $80,9 \%$ yang mengkonsumsi tablet tambah darah [3]

Kepatuhan dalam mengkonsumsi tablet tambah darah adalah ketaatan remaja putri melaksanakan anjuran petugas kesehatan untuk mengkonsumsi tablet tambah darah. Kepatuhan mengkonsumsi tablet tambah darah di ukur dari ketepatan jumlah tablet yang dikonsumsi, ketepatan cara mengkonsumsi tablet tambah darah, frekuensi konsumsi perhari.

Promosi kesehatan merupakan salah satu upaya untuk meningkatkan kemampuan masyarakat melalui pembelajaran dari, oleh, untuk dan bersama masyarakat, agar mereka dapat menolong diri sendiri, serta mengembangkan kegiatan yang bersumber daya masyarakat, sesuai sosial budaya setempat dan didukung kebijakan publik yang berwawasan kesehatan [4]
Salah satu lingkup promosi kesehatan dilakukan dengan metode ceramah dan diskusi kelompok mengenai masalah kesehatan. Metode Ceramah adalah cara yang digunakan dalam menyampaikan pesan kesehatan dan informasi kepada individu, kelompok dan masyarakat secara lisan. Sedangkan Diskusi kelompok kecil atau Small Group Discussion merupakan salah satu elemen belajar secara aktif [5]

Dari data [6] Kota Pekanbaru, Persentase Remaja Putri Mendapat Tablet Tambah Darah (TTD) baru mencapai 30\%. Pemerintah melalui BKKBN membuat program PIK (Pusat Informasi Konseling Remaja), dimana PIK merupakan suatu wadah yang dikelola dari oleh dan untuk remaja guna memberikan pelayanan informasi dan konseling tentang perencanaan kehidupan berkeluarga bagi remaja serta kegiatan-kegiatan penunjang lainnya. Dari 44 SMP Negeri yang ada di kota Pekanbaru,. Salah satu SMP Negeri yang memiliki PIK adalah SMP Negeri 16. SMP Negeri 16 memiliki jumlah siswi sebanyak 384 orang.

Berdasarkan survei awal didapatkan hasil bahwa $70 \%$ siswi tidak mengkonsumsi tablet tambah darah dan hanya 30\% siswi yang mengkonsumsi tablet tambah darah tetapi tidak rutin hanya pada saat membutuhkannya saja.

Penelitian ini bertujuan untuk mengetahui efektivitas metode ceramah dan diskusi kelompok terhadap kepatuhan remaja dalam mengkomsumsi tablet tambah darah di SMP Negeri 16 Kota Pekanbaru, sehingga remaja khususnya remaja putri dapat mengetahui manfaat mengkonsumsi tablet tambah darah dalam mencegah terjadinya anemia.

Berdasarkan latar belakang diatas, maka peneliti tertarik untuk melakukan penelitian tentang "Efektivitas Metode Ceramah Dan Diskusi Kelompok Terhadap Kepatuhan Remaja Dalam Mengkomsumsi Tablet Tambah Darah“. 


\section{TINJAUAN PUSTAKA}

Hasil penelitian R. M. Kansil JF, Katuuk ME tahun 2019 tentang pengaruh pemberian edukasi dengan metode focus group discussion terhadap kepatuhan minum obat penderita hipertensi di puskesmas tahuna barat, didapatkan hasil metode edukasi dengan FGD sangat efektif digunakan untuk meningkatkan kepatuhan minum obat penderita hipertensi di Puskesmas Tahuna Barat. [7]

Hasil penelitian F. N. Yulinda A tahun 2018 tentang efektivitas penyuluhan metode ceramah dan audiovisual dalam meningkatkan pengetahuan dan sikap tentang sadari di SMKN 5 surabaya didapatkan hasil terdapat peningkatan tingkat pengetahuan dan sikap sebelum dan sesudah penyuluhan kesehatan. Remaja putri dengan tingkat pengetahuan baik meningkat dari $80 \%$ menjadi $93,75 \%$. Remaja putri dengan sikap positif $32,5 \%$ dan meningkat menjadi 90\%. [8]

Promosi kesehatan merupakan salah satu upaya untuk meningkatkan kemampuan masyarakat melalui pembelajaran, dengan adanya promosi kesehatan masyarakat akan mendapatkan ilmu yang akan berdampak kepada peningkatan pengetahuannya, dengan pengetahuan yang meningkat akan berdampak kepada peningkatan sikap kearah yang lebih positif, setelah pengetahuan dan sikap berubah ke arah yang lebih baik akan berdampak kepada tindakan atau perilaku seseorang untuk menjadi lebih baik atau taat terhadap peraturan.

Kepatuhan yang didasari akan pengetahuan dan sikap akan bertahan lama, karena didasari akan kesadaran akan pentingnya sesuatu yang dilakukannya.

\section{METODE}

Jenis penelitian adalah kuantitatif, desain Quasi eksperimen menggunakan metode Nonquivalent Control Group Design [9]. Penelitian dilakukan di SMP Negeri 16 Kota Pekanbaru pada bulan November 2019. Populasi penelitian adalah seluruh remaja putri di SMP Negeri 16 Kota Pekanbaru berjumlah 384 orang. Sampel adalah remaja puteri umur 15 tahun yang berjumlah 60 Orang. Umur 15 tahun dipakai karena pada umur 15 tahun sebagian besar remaja putri telah menstruasi. Pengambilan sampel dilakukan dengan cara total sampling [10]. Instrumen penelitian adalah kuesioner. Pengolahan data dengan editing, coding, Entry dan tabulating. Analisa yang digunakan adalah univariat dan bivariat, menggunakan uji Ttest dependent/ $t$ - paired test. [11]

\section{HASIL DAN PEMBAHASAN}

Berdasarkan analisis data secara univariat dengan menganalisis hasil dari tiap-tiap variabel penelitian yang terdiri dari kepatuhan remaja puteri dalam mengkonsumsi tablet tambah darah terhadap efektivitas promosi kesehatan metode ceramah dan diskusi kelompok 
Tabel 1.

Distribusi Frekuensi Kepatuhan Remaja Dalam Mengkonsumsi Tablet Tambah Darah Sebelum Dan Sesudah Dilakukan Metode Ceramah

\begin{tabular}{ccccc}
\hline \multirow{2}{*}{ Kepatuhan } & \multicolumn{2}{c}{ Rendah } & \multicolumn{2}{c}{ Tinggi } \\
\cline { 2 - 5 } & $\mathbf{F}$ & $\mathbf{( \% )}$ & $\mathbf{F}$ & $\mathbf{( \% )}$ \\
\hline Pretest & 13 & 44 & 17 & 56 \\
Postest & 7 & 23 & 23 & 77 \\
\hline
\end{tabular}

Berdasarkan tabel 1 diketahui bahwa dari 30 remaja putri di SMP Negeri 16 Kota Pekanbaru yang menjadi responden, sebelum dilakukan metode ceramah diketahui responden yang memiliki kepatuhan tinggi sebanyak 17 orang $(56 \%)$ dan rendah sebanyak 13 orang
(44\%), setelah dilakukan metode ceramah, diketahui kepatuhan responden dalam mengkonsumsi tablet tambah darah mengalami peningkatan menjadi tinggi sebanyak 23 orang $(77 \%)$ dan rendah sebanyak 7 orang $(23 \%)$.

Tabel 2.

Distribusi Frekuensi Kepatuhan Remaja Dalam Mengkonsumsi Tablet Tambah Darah Sebelum Dan Sesudah Dilakukan Diskusi Kelompok

\begin{tabular}{ccccc}
\hline \multirow{2}{*}{ Kepatuhan } & \multicolumn{2}{c}{ Rendah } & \multicolumn{2}{c}{ Tinggi } \\
\cline { 2 - 5 } & F & $(\boldsymbol{\%})$ & F & $(\boldsymbol{\%})$ \\
\hline Pretest & 14 & 47 & 16 & 53 \\
Postest & 3 & 10 & 27 & 90 \\
\hline
\end{tabular}

Berdasarkan tabel 2 diketahui bahwa dari 30 remaja putri di SMP Negeri 16 Kota Pekanbaru yang menjadi responden, sebelum dilakukan diskusi kelompok diketahui responden yang memiliki kepatuhan tinggi sebanyak 16 orang $(53 \%)$ dan rendah sebanyak 14 orang (47\%), setelah dilakukan diskusi kelompok, diketahui kepatuhan responden dalam mengkonsumsi tablet tambah darah mengalami peningkatan menjadi tinggi sebanyak 27 orang $(90 \%)$ dan rendah sebanyak 3 orang (10\%).
Berdasarkan analisis data secara bivariat untuk mengetahui perbedaan kepatuhan pada kelompok eksperimen dan kelompok kontrol sebelum dan sesudah dilakukan metode ceramah dan diskusi kelompok, dengan menggunakan uji T- test ( $t$-dependent/ t-paired test). Apabila $\mathrm{p}$ value $<\alpha(0,05)$ maka terdapat perbedaan antara metode ceramah dan diskusi kelompok, sebaliknya apabila $\mathrm{p}$ value $>\alpha$ $(0,05)$ maka tidak ada perbedaan antara metode ceramah dan diskusi kelompok. Hasil analisa bivariat dalam penelitian ini dapat dilihat pada tabel sebagai berikut: 
Tabel 3.

Perbedaan Kepatuhan Remaja Dalam Mengkonsumsi Tablet Tambah Darah Sebelum Dan Sesudah Dilakukan Metode Ceramah

\begin{tabular}{cccccccccc}
\hline & \multicolumn{2}{c}{ Rendah } & \multicolumn{2}{c}{ Tinggi } & Mea & SD & SE & P Value & N \\
\cline { 2 - 6 } Kepatuhan & F & $(\boldsymbol{\%})$ & F & $(\boldsymbol{\%})$ & $\mathbf{n}$ & & & & \\
\hline PreTest & 13 & 44 & 17 & 56 & 6.75 & 1.276 & 0.202 & 0.000 & 30 \\
Postest & 7 & 23 & 23 & 77 & 7.95 & 0.986 & 0.156 & 0.000 & 30 \\
\hline
\end{tabular}

Berdasarkan tabel 3 diketahui bahwa dari bahwa dari 30 remaja putri di SMP Negeri 16 Kota Pekanbaru yang menjadi responden, sebelum dilakukan metode ceramah diketahui responden yang memiliki kepatuhan tinggi sebanyak 17 orang $(56 \%)$ dan rendah sebanyak 13 orang $(44 \%)$ dengan mean atau rata-rata 6.75 dan standar deviasi 1.276, setelah dilakukan metode ceramah, diketahui kepatuhan responden dalam mengkonsumsi tablet tambah darah mengalami peningkatan menjadi tinggi sebanyak 23 orang $(77 \%)$ dan rendah sebanyak 7 orang (23\%) dengan mean 7.95 dan standar deviasi adalah 0.986. Hasil uji statistik didapatkan nilai $\mathrm{P}$ value $=0,000 \quad(0,000<0,05)$ maka dapat disimpulkan ada perbedaan yang signifikan antara kepatuhan sebelum dan sesudah dilakukan promosi kesehatan menggunakan metode ceramah

Tabel 4.

Perbedaan Kepatuhan Remaja Dalam Mengkonsumsi Tablet Tambah Darah Sebelum Dan Sesudah Dilakukan Diskusi Kelompok

\begin{tabular}{cccccccccc}
\hline & \multicolumn{2}{c}{ Rendah } & \multicolumn{2}{c}{ Tinggi } & Mean & SD & SE & P Value & N \\
\cline { 2 - 6 } Kepatuhan & $\mathbf{F}$ & $(\boldsymbol{\%})$ & $\mathbf{F}$ & $\mathbf{( \% )}$ & & & & & \\
\hline Pretest & 14 & 47 & 16 & 53 & 6.25 & 1.498 & 0.237 & 0.000 & 30 \\
Postest & 3 & 10 & 27 & 90 & 9.15 & 1.027 & 0.162 & 0.000 & 30 \\
\hline
\end{tabular}

Berdasarkan tabel 4 diketahui bahwa dari 30 remaja putri di SMP Negeri 16 Kota Pekanbaru yang menjadi responden, sebelum dilakukan diskusi kelompok. Diketahui responden yang memiliki kepatuhan tinggi sebanyak 16 orang (53\%) dan rendah sebanyak 14 orang $(47 \%)$ dengan mean atau rata-rata 6.25 dan standar deviasi 1.498, setelah dilakukan diskusi kelompok, diketahui kepatuhan responden dalam mengkonsumsi tablet tambah darah mengalami peningkatan menjadi tinggi sebanyak 27 orang $(90 \%)$ dan rendah sebanyak 3 orang (10\%) dengan mean 9,15 dan standar deviasi adalah 1, 027. Hasil uji statistik didapatkan nilai $\mathrm{P}$ value $=0,000$ $(0,000<0,05)$ maka dapat disimpulkan ada perbedaan yang signifikan antara kepatuhan sebelum dan sesudah dilakukan diskusi kelompok. 
Tabel 5.

Perbedaan Kepatuhan Remaja Dalam Mengkonsumsi Tablet Tambah Darah Sesudah Dilakukan Metode Ceramah Dan Diskusi Kelompok

\begin{tabular}{ccclcr}
\hline Variabel & Me & \multicolumn{1}{c}{ S } & \multicolumn{1}{c}{ SE } & \multicolumn{1}{c}{$\mathbf{P}$} & I \\
Value & \\
\hline Kepatuhan Sesudah Promosi Kesehatan & 7.9 & 0. & 0.15 & 0.000 & 3 \\
Menggunakan Metode Ceramah & 5 & 986 & 6 & & 0 \\
\hline Kepatuhan Sesudah Promosi Kesehatan & 9.1 & 1. & 0.16 & 0.000 & 3 \\
Menggunakan Diskusi Kelompok & 5 & 027 & 2 & & 0 \\
\hline
\end{tabular}

Berdasarkan tabel 5 dapat dilihat mean atau rata-rata kepatuhan sesudah metode ceramah adalah 7.95 dengan standar deviasi 0.986, sedangkan untuk diskusi kelompok mean atau rata-rata kepatuhan adalah 9.15 dan standar deviasi adalah 1.027. Hasil uji statistik didapatkan nilai $\mathrm{P}$ value $=$ $0,000(0,000<0,05)$ maka dapat disimpulkan bahwa promosi kesehatan yang paling efektif dalam meningkatkan kepatuhan remaja putri dalam mengkonsumsi tablet tambah darah adalah dengan menggunakan diskusi kelompok

\section{Efektivitas Metode Ceramah Terhadap Kepatuhan Remaja Putri Dalam Mengkonsumsi Tablet Tambah Darah}

Hasil penelitian didapatkan terdapat perbedaan kepatuhan remaja putri dalam mengkonsumsi tablet tambah darah sebelum dan sesudah dilakukan metode ceramah.

Menurut Notoadmodjo (2012) kepatuhan merupakan perilaku individu sesuai anjuran terapi dan kesehatan. Dapat disimpulkan perilaku sebagai semua kegiatan atau aktivitas manusia, baik yang dapat diamati langsung, maupun yang tidak dapat diamati oleh pihak luar. [12]

Meskipun perilaku adalah bentuk respons atau reaksi terhadap stimulus atau rangsangan dari luar organisme (orang), namun dalam memberikan respons sangat tergantung pada karakteristik atau faktorfaktor lain dari orang yang bersangkutan. Stimulusnya dalam hal ini sama bagi beberapa orang, namun respons tiap-tiap orang berbeda [4].
Faktor-faktor yang membedakan respons terhadap stimulus yang berbeda disebut determinan perilaku. Determinan perilaku ini antara lain : faktor internal, misalnya tingkat kecerdasan, tingkat emosional, jenis kelamin, dan sebagainya dan faktor eksternal, misalnya lingkungan, baik fisik, sosial, budaya, ekonomi, politik dan sebagainya. Faktor lingkungan ini sering merupakan faktor yang dominan yang mewarnai perilaku seseorang [4]

Informasi merupakan salah satu faktor eksternal yang mempengaruhi perilaku seseorang. Kemudahan untuk memperoleh suatu informasi dapat membantu mempercepat seseorang untuk mengubah perilaku menjadi yang lebih baik [13]

Promosi Kesehatan adalah kegiatan atau usaha penyampaikan pesan kesehatan kepada masyarakat, kelompok atau individu. Dengan harapan bahwa dengan adanya pesan tersebut, maka masyarakat, kelompok atau individu dapat memperoleh pengetahuan tentang kesehatan yang lebih baik. Pengetahuan tersebut pada akhirnya diharapkan dapat berpengaruh terhadap perilaku. [4]

Hasil penelitian ini sejalan dengan penelitian yang dilakukan F. N. Yulinda A (2018) tentang efektivitas penyuluhan metode ceramah dan audiovisual dalam meningkatkan pengetahuan dan sikap tentang sadari di SMKN 5 surabaya didapatkan hasil terdapat peningkatan tingkat pengetahuan dan sikap sebelum dan sesudah penyuluhan kesehatan. Remaja putri dengan tingkat pengetahuan baik meningkat dari $80 \%$ menjadi $93,75 \%$. Remaja putri dengan sikap 
positif $32,5 \%$ dan meningkat menjadi $90 \%$. [8]

Menurut asumsi peneliti masih rendahnya kepatuhan remaja putri dalam mengkonsumsi tablet tambah darah dikarenakan kurangnya pemahaman remaja putri tentang manfaat dari tablet tambah darah, sehingga remaja putri merasa tidak perlu mengkonsumsi tablet tambah darah tersebut secara rutin, sehingga kepatuhan remaja putri dalam mengkonsumsi tablet tambah darah masih rendah.

\section{Efektivitas Metode Diskusi Kelompok Terhadap Kepatuhan Remaja Putri Dalam Mengkonsumsi Tablet Tambah Darah}

Hasil penelitian didapatkan terdapat perbedaan kepatuhan remaja putri dalam mengkonsumsi tablet tambah darah sebelum dan sesudah dilakukan diskusi kelompok

Salah satu faktor yang mempengaruhi kepatuhan sesorang adalah lingkungan. Lingkungan merupakan suatu kondisi yang ada disekitar manusia dan dapat mempengaruhi perkembangan dan perilaku orang atau kelompok. [14]

Promosi kesehatan merupakan suatu proses dimana proses tersebut mempunyai masukan (input) dan keluaran (output). Promosi kesehatan bertujuan untuk mencapai perilaku kesehatan (healthy behavior), selain berubahnya masyarakat menjadi masyarakat yang melek kesehatan (healthy literacy). Pada akhirnya pendidikan tidak hanya diketahui atau disadari (knowledge) tapi juga akan disikapi (attitude). Sesuai dengan keterangan tersebut, dengan pelaksanaan diskusi kelompok pada remaja putri tentang tablet tambah darah akan meningkatkan pengetahuan, sikap dan tindakan responden yang pada akhirnya akan merubah perilaku responden yang dari sebelumnya tidak mengkonsumsi tablet tambah darah menjadi mengkonsumsi tablet tambah darah. [4]

Diskusi adalah salah satu elemen belajar secara aktif. Pendekatan kelompok memang suatu waktu diperlukan dan perlu digunakan untuk membina dan mengembangkan sikap sosial anak didik. Dengan pendekatan kelompok, diharapkan dapat ditumbuh kembangkan rasa sosial yang tinggi pada diri setiap anak didik. Dalam diskusi kelompok agar semua kelompok dapat bebas berpartisipasi dalam diskusi, maka formasi duduk diantara para peserta diatur sedemikian rupa sehingga mereka dapat berhadap-hadapan atau saling memandang satu sama lain. Dengan kata lain mereka harus merasa dalam taraf yang sama sehingga tiap anggota kelompok mempunyai kebebasan atau keterbukaan untuk mengeluarkan pendapat. Agar terjadi diskusi yang hidup maka pemimpin kelompok harus mengarahkan dan mengatur sedemikian rupa sehingga semua orang dapat kesempatan berbicara, sehingga tidak menimbulkan dominasi dari salah seorang peserta [15]

Hasil penelitian ini sejalan dengan hasil penelitian [7] tentang pengaruh pemberian edukasi dengan metode focus group discussion terhadap kepatuhan minum obat penderita hipertensi di puskesmas tahuna barat, didapatkan hasil metode edukasi dengan FGD sangat efektif digunakan untuk meningkatkan kepatuhan minum obat penderita hipertensi di Puskesmas Tahuna Barat.

Penelitian serupa juga dilakukan oleh Wijiastuti (2011) tentang efektivitas penyuluhan dengan metode diskusi kelompok dalam meningkatkan pengetahuan, sikap dan perilaku ibu tentang pencegahan pneumonia pada balita di wilayah puskesmas banjarnegara. Dari hasil penelitian didapatkan bahwa penyuluhan dengan metode diskusi kelompok efektif dalam meningkatkan pengetahuan dan perilaku ibu balita tentang pneumonia balita. Hasil uji statistik diperoleh nilai $\mathrm{P}$ value $=0,000(\mathrm{P}<0,05)$. [16]

Menurut asumsi peneliti masih rendahnya kepatuhan remaja putri dalam mengkonsumsi tablet tambah darah dikarenakan kurangnya pemahaman dan dukungan dari lingkungan terhadap remaja putri tentang tablet tambah darah, sehingga kepatuhan remaja putri dalam mengkonsumsi tablet tambah darah masih rendah. Lingkungan akan memberikan informasi kepada seseorang, dengan informasi yang didapat seseorang akan memperoleh 
pengetahuan tentang kesehatan yang lebih baik. Pengetahuan tersebut pada akhirnya diharapkan dapat berpengaruh terhadap perilaku. Dengan kata lain setelah responden mengetahui tentang tablet tambah darah, responden menjadi berfikir manfaat dari tablet tambah darah bagi tubuhnya sehingga membuat responden berperilaku untuk patuh mengkonsumsi tablet tambah darah. Pengetahuan yang tinggi dan sikap yang positif akan menghasilkan kepatuhan yang secara sadar akan dilakukan oleh seseorang.

\section{Perbedaan Kepatuhan Remaja Putri Dalam Mengkonsumsi Tablet Tambah Darah Sesudah Dilakukan Metode Ceramah Dan Diskusi Kelompok}

Hasil penelitian didapatkan promosi kesehatan yang paling efektif dalam meningkatkan kepatuhan remaja putri dalam mengkonsumsi tablet tambah darah adalah dengan diskusi kelompok.

Hal ini sejalan dengan teori D. Wawan (2010) pengetahuan terbentuk salah satunya karena adanya rasa ketertarikan terhadap materi atau ilmu yang ada, sehingga seseoranga akan mulai menaruh perhatian atau tertarik pada suatu objek. Kelompok diskusi kecil atau Small Group Discussion bersifat menarik karena dalam diskusi kelompok semua kelompok dapat bebas berpartisipasi dan bebas mengemukakan pendapat dalam penyelesaian permasalahan [14]

Hasil penelitian ini sesuai dengan penelitian yang dilakukan E. Akbar ZSL, Lumongga, NL, Yahrial (2013) tentang Pengaruh Penyuluhan Dengan Metode Ceramah dan Diskusi Terhadap Peningkatan Pengetahuan Dan Sikap Anak tentang PHBS di Sekolah Dasar Negeri 014 Kelurahan Namogajah Kecamatan Medan Tuntungan, didapatkan hasil bahwa metode yang sangan efektif dalam meningkatkan pengetahuan dan Sikap anak tentang PHBS adalah metode diskusi [17]

Menurut asumsi peneliti diskusi kelompok merupakan metode promosi kesehatan yang paling efektif dalam penelitian ini karena dalam diskusi kelompok, responden tidak hanya diberikan pemahaman tentang tablet tambah darah, tetapi responden juga diajak berfikir akan manfaat dan dampak dari tidak mengkonsum tablet tambah darah terhadap dirinya melalui tukar pengalaman yang dilakukan sesama kelompok diskusi sehingga pemahaman responden terhadap tablet tambah darah menjadi semakin kuat yang akan berdampak kepada kepatuhannya terhadap konsumsi tablet tambah darah

\section{KESIMPULAN}

Terdapat perbedaan kepatuhan remaja putri dalam mengkonsumsi tablet tambah darah sebelum dan sesudah dilakukan promosi kesehatan menggunakan metode ceramah dan diskusi kelompok. Promosi kesehatan yang paling efektif dalam meningkatkan kepatuhan remaja putri dalam mengkonsumsi tablet tambah darah adalah dengan menggunakan diskusi kelompok.

\section{DAFTAR PUSTAKA}

[1] Soetjiningsih, Tumbuh Kembang Remaja Dan Permasalahannya. jakarta: CV Sagung Seto, 2010.

[2] R. Kemenkes, "Peraturan Menteri Kesehatan RI No 88 Tahun 2014 Tentang Standar Tablet Tambah Darah Bagi Wanita Usia Subur Dan Ibu Hamil," jakarta, 2014.

[3] R. Kemenkes, "Riset Kesehatan Dasar (Riskesdas)," jakarta, 2018.

[4] Notoatmodjo, Promosi Kesehatan Teori dan Aplikasi. Jakarta: Rineka Cipta, 2010.

[5] Waryana, Promosi Kesehatan, Penyuluhan, dan Pemberdayaan Masyarakat. Yogyakarta: Nuha Medika, 2016.

[6] K. P. Dinas kesehatan, "Profil Kesehatan Kota Pekanbaru Tahun 2017," Dinas Kesehatan Kota 
Pekanbaru, Pekanbaru, 2017.

[7] R. M. Kansil JF, Katuuk ME, "Pengaruh Pemberian Eduksai Dengan Metode Focux Group Discussion Terhadap Kepatuhan Minum Obat Penderita Hipertensi Di Puskesmas Tahuna Barat," E-Jurnal Keperawatan (e-Kp), vol. Vol 7, 2019.

[8] F. N. Yulinda A, "Efektivitas Penyuluhan Metode Ceramah Dan Audiovisual Dalam Meningkatkan Pengetahuan Dan Sikap Tentang Sadari Di SMKN 5 Surabaya," J. Promkes, vol. Vol 6, 2018.

[9] Sugiyono, Metode Penelitian Kuantitatif, Kualitatif Dan $R \& D$. Bandung: Alfabeta, 2016.

[10] Hidayat, Metode Peneltian Kebidanan dan Teknik Analisa Data. jakarta: Salemba Medika, 2012.

[11] Notoadmodjo, Metode Penelitian Kesehatan. jakarta: Rineka Cipta, 2012.

[12] Kozier, Buku Ajar Keperawatan Klinis Edisi 5. jakarta: EGC, 2010.
[13] Mubarak, Ilmu Kesehatan Masyarakat Teori Dan Aplikasi. jakarta: Salemba Medika, 2009.

[14] D. Wawan, Teori \& Pengukuran Pengetahuan, Sikap Dan Perilaku Manusia. Yogyakarta: Nuha Medika, 2010.

[15] Djamarah, Strategi Belajar Mengajar. Jakarta: Rineka Cipta, 2010.

[16] Wijiastuti, "Efektivitas Penyuluhan Dengan Metode Diskusi Kelompok Dalam Meningkatkan Pengetahuan, Sikap Dan Perilaku Ibu Tentang Pencegahan Pneumonia Pada Balita Di Wilayah Puskesmas Banjarnegara," Universitas Negeri Semarang, 2011.

[17] E. Akbar ZSL, Lumongga, NL, Yahrial, "Pengaruh Penyuluhan Dengan Metode Ceramah Dan Diskusi Terhadap Peningkatan Pengetahuan Dan Sikap Anak Tentang Phbs Di Sekolah Dasar Negeri 065014 Kelurahan Namogajah Kecamatan Medan Tuntungan Tahun 2013," J. USU, vol. Vol 2, 2013. 